\title{
THE OSCILLATION RESISTANCE RATIO (ORR) FOR UNDERSTANDING INELASTIC RESPONSE
}

\author{
Hossein Soleimankhani ${ }^{1}$, Gregory MacRae ${ }^{2}$ \\ and Timothy Sullivan ${ }^{3}$
}

(Submitted August 2020; Reviewed October 2020; Accepted April 2021)

\begin{abstract}
Single-storey systems with different hysteretic characteristic are subjected to impulse-type short duration and long duration earthquake records to investigate the effects of hysteretic behaviour and ground motion characteristics on the seismic response. EPP, bilinear, Takeda, SINA, and flag-shaped hysteretic models loops are considered and an energy approach is taken to explain the inelastic behaviour. The first part of the work is based on analyses of the single-storey systems without any torsion, however; torsional irregularity is considered in the later analyses.

It is shown that structures with the same backbone curve, but different hysteretic characteristics, tend to experience the same maximum response under short duration earthquake records, where there is one major displacement excursion. The likelihood of further displacement in the reverse (i.e. negative) direction is characterized using energy methods and free vibration analyses along with a new proposed "oscillation resistance ratio (ORR)" are employed to improve the understanding of the seismic response. Hysteretic models with low $O R R$, such as SINA and flag-shaped, are shown to have a greater likelihood of higher absolute displacement response in the negative direction compared with those with fatter hysteretic loops. The understanding of the response in terms of energy reconciles some differences in the ability of initial stiffness versus secant stiffness based methods to predict peak displacement demands with account for different ground motion characteristics.

The same peak displacements in the primary direction was also observed for structures with stiffness/strength eccentricities under an impulse-type earthquake record. However, during unloading, the elastic energy stored in the out-of-plane elements is released causing greater displacement on the weak side in the reverse direction.
\end{abstract}

\section{INTRODUCTION}

Damage to structural elements in yielding building systems subjected to earthquake shaking is related to the deformations they experience. Design is generally conducted so that the deformation (and hence damage) demands are less than the damage capacity for the limit state and shaking level considered. Two simple empirical approaches are commonly used as the basis for prediction of structural displacement demand by practitioners in design. Neither approach has a strong fundamental basis in the actual behaviour. They are applied to regular and slightly irregular single and multi-storey structures. They were developed from the response of yielding single-degree-of-freedom (SDOF) systems from elastic response spectra characteristics.

The first, which is commonly used in common design standards, computes displacements of structures based on their initial stiffness. The method is fundamentally independent of the structure unloading and energy dissipation characteristic. The second approach is based on the structure secant stiffness and hysteretic damping. The original concept was that at the peak displacement the structure oscillates with equal magnitude in both directions (which is seldom true in reality). This, in its fundamental form, the peak response decreases with increased in hysteretic loop energy dissipation. This approach is more often used for structures with more pinched hysteretic behaviour. Both approaches have been calibrated for typical structural types and earthquake records to reasonably estimate seismic displacements. Nevertheless, differences in response estimation exist as a result of the fundamental assumptions, the type of earthquake record used, and the specific calibration performed.

It may be seen from the discussion above that while satisfactory empirical methods exist to estimate the displacement response for design, these methods do not have a strong fundamental basis. For good design, it is desirable that a rational understanding of behaviour be developed based on the response of single-storey structures subject to records of different types that can be applied to irregular and multi-storey structures.

This paper seeks to address these issues by seeking answers to the following questions:

1. What are the displacements of single storey structures with the same backbone curve but different hysteretic characteristics subject to impulse records?

2. What are the displacements of these structures subject to realistic earthquake records?

3. Can a simple method be developed to understand the response of structure with different hysteresis loops considering the shaking type?

4. How do the concepts developed relate to single storey structures subject to torsional deformation? 


\section{Initial Stiffness and Secant Stiffness Based Displacement Prediction Methods}

Initial stiffness based methods are based on the assumption that the inelastic response may be predicted from the elastic response considering a modification for ductility and structural period. Two widely known relationships which estimate inelastic displacement based on just the initial stiffness of the structure are the equal displacement assumption (EDA) and the equal energy assumption (EEA) [1]. For medium to long period structures, it is often assumed in design that the inelastic displacement is equal to the displacement of an equivalent elastic system with the same initial stiffness and therefore $R=$ $\mu$, where $R$ is the ratio of the elastic force to yield strength and $\mu$ is the ratio of the ultimate displacement to the yield displacement (Figure 1), which is known as the EDA. For shorter period structures, the inelastic displacements are often larger than elastic displacements, which means $R<\mu$. Newmark and Hall observed that the EEA is applicable to moderately short period structures, which leads to $R=\sqrt{2 \mu-1}$ [2]. EEA states that the monotonic loading energy (please see Figure 13) for elastic and elastic-perfectlyplastic structures is the same when subjected to the same seismic event. FEMA 356 [3] introduces an empirical factor (the $C_{1}$ in Equation (3-15)) to modify the displacement calculated for the linear response to the inelastic response for short period structures [3]. $R-\mu-T$ relationships have been investigated by many people including Priestley et al. [4], MacRae [5], Miranda et al. [6]. Miranda et al. discussed and evaluated the accuracy of these $R-\mu-T$ relations in detail [6].

The displacement demand on an inelastic system may be affected by the hysteretic characteristics of the structural elements [7]. According to FEMA 356, for structures with low energy dissipation such as pinched hysteretic structures (e.g. rocking structures), EDA may underpredict the actual displacements so modifications have been proposed to predict the displacement demands better (i.e. the $C_{2}$ factor used in Equation (3-15) to represent the effect of pinched hysteresis shape [3]).

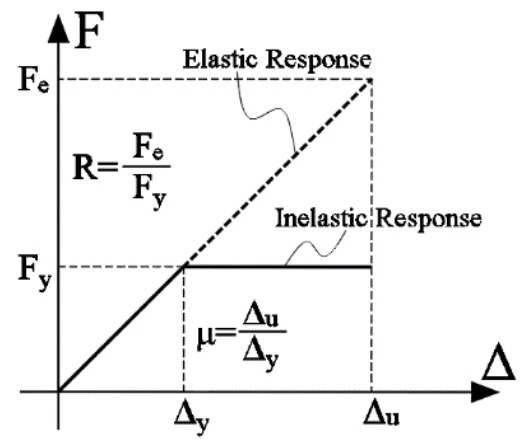

\section{Figure 1: Illustration of the equal displacement assumption.}

The idea of using an elastic substitute structure was first introduced by Jacobsen [8]. His approach, also followed by Gulkan et al. [9], is based on the concept that the energy absorbed by the hysteretic cyclic response of a yielding structure in its steady state is equal to the energy dissipated by the equivalent viscous damping (EVD) of a substitute structure, $\xi_{\text {hyst, }}$, with an elastic stiffness equal to the secant stiffness at the peak displacement. This is expressed in Equation ( (1). This approach is used in documents such as ATC-40. It provides procedures for the seismic evaluation and retrofit of concrete buildings [10]. $\xi_{e q}=\xi_{0}+\xi_{\text {hyst }}=\xi_{0}+\frac{2}{\pi} \frac{A_{\text {hyst }}}{A_{m}}=\xi_{0}+\frac{A_{\text {hyst }}}{2 \pi F_{m} \Delta_{m}}$

where, $\quad \xi_{0}=$ initial elastic damping ratio;

$A_{\text {hyst }}=$ complete stabilized hysteresis loop area, the hatched area shown in Figure 2;

$A_{\mathrm{m}}=$ rectangular area within the maximum force, $F_{\mathrm{m}}$, and displacement, $\Delta \mathrm{m}$ as shown in Figure 2.

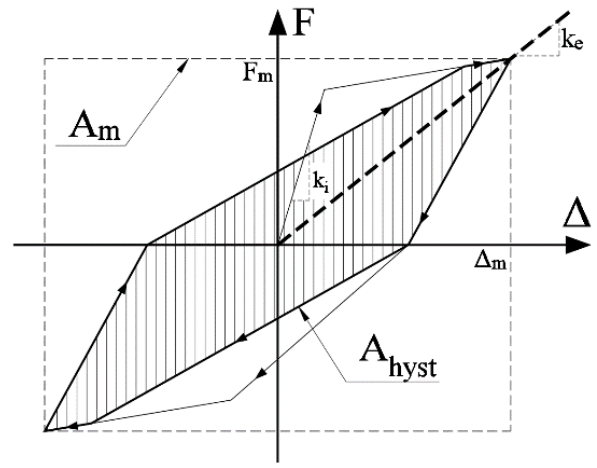

Figure 2: Hysteretic area for EVD calculation.

Equation ( (1) resulted in displacements close to those predicted by time history analysis for systems with pinched hysteretic behaviour, such as those using the Takeda loop, but often underestimated the displacement of systems with high energy dissipating capacity such as the bilinear model for which the initial stiffness proportional method was found to be better for fatter hysteretic loops [11]. In order to improve the accuracy of the substitute structure method, Priestley et al. [11] used the results of non-linear time-history analyses (NTHA) to calibrate EVD values for different hysteretic models to predict the same peak displacement. Therefore, this approach is empirical and its accuracy will depend on the characteristics of the ground motions used in calibration studies compared to those expected at the site. Indeed, researchers such as Pennucci et al. [12] and Stafford et al. [13] showed that spectral shape and earthquake magnitude would also affect calibration results.

In Priestley's approach, the equivalent damping for structures with fat hysteretic loops become similar indicating that for these structures the hysteretic loop unloading characteristics do not affect the peak response. For example, the effect of damping for Takeda and bilinear hysteretic loops are almost identical [7]. This is consistent with the initial stiffness-based concepts.

From the discussion above, it would appear that the success of a given approach would greatly depend on the characteristics of the imposed shaking, because this affects the calibration. Both the initial and secant stiffness based approaches have therefore been modified to provide results that are more realistic. Sullivan showed that the choice of properly calibrated displacement prediction methods does not affect the design strength significantly so long as the designer has made consistent assumptions [14].

\section{METHODOLOGY}

A numerical model of a single-storey structure with various hysteretic characteristics is subject to earthquake records causing different shaking response to quantify displacement response and to develop new concepts affecting peak response estimation. A full parametric study is not undertaken, as it is not necessary to satisfy the aims stated in the introduction. 


\section{Numerical Model}

A numerical model of a single-storey structure, shown in Figure 3, is employed for analyses in this work. The model is subjected to an impulse load as well as ground shaking and the results are used to explain the inelastic response of the oscillators with different hysteretic behaviour. The structure is assumed rectangular in plan with width, $B$, of $24 \mathrm{~m}$ and length, $L$, of $40 \mathrm{~m}$. Two seismic force resisting system (SFRS) are considered in each direction. The diaphragm is assumed rigid and the total mass, $M$, and mass rotational inertia, $I_{\text {rot }}$, of the system are lumped at the centre of mass, $C_{\mathrm{M}}$, which is at the centre of the rectangular plan. As shown in Figure 3, the structure is shaken only in the $y$ direction.

In the first stage of this work, the total stiffness and strength of the system is divided equally between SFRSs in the $y$ direction, which are $14 \mathrm{~m}$ away from $C_{\mathrm{M}}$. The SFRSs in the $x$ direction are both of the same stiffness and strength and placed at a distance of $9 \mathrm{~m}$ from $C_{\mathrm{M}}$. Therefore, there is no stiffness/strength eccentricity and this structure acts like a SDOF system under excitation in the $y$ direction even though it has more than one element (i.e. the translation of the rigid floor in the $y$ direction is the only degree of freedom of the system)

The system total initial lateral stiffness, $K_{i}$, was calculated according to Equation (2) for the specified mass, $M$, to obtain a fundamental period, $T$, of $1.0 \mathrm{~s}$. The mass specified is not important as it does not affect the behaviour, but the value chosen is given in Table 2. A structure with a period of $1 \mathrm{~s}$ may be representative of a $4 \sim 5$ storey building structure designed in high seismic regions and selected as an illustrative example.

$K_{i}=\left(\frac{2 \pi}{T}\right)^{2} M$

The total system lateral yield strength, $F_{\mathrm{y}}$, was specified such that the ratio of the total lateral strength to the total seismic weight of the system, $C_{\mathrm{y}}$, was 0.1 according to Equation (Error! Reference source not found. where $g$ is the acceleration of gravity.

$F_{y}=C_{y}(M \times g)$

According to NZS 1170.5, the standard used in New Zealand, to calculate the force and deformation demands on structures from earthquake shakings [15], $C_{\mathrm{y}}=0.1$ roughly represents a medium range period (e.g. $T \approx 1 \mathrm{~s}$ ) ductile structure (e.g. $\mu \approx$ 4 ) in a seismic region (e.g. $Z \approx 0.4$ ). Table 1 lists the parameters defining the SDOF system.
Table 1: SDOF System parameters.

\begin{tabular}{lcl} 
Parameter & Value & Unit \\
\hline Mass (M) & $4.00 \times 10^{6}$ & N.s $/ \mathrm{m}$ (i.e. kg) \\
Period (T) & 1.00 & $\mathrm{~s}$ \\
Total initial stiffness (Ki) & $1.58 \times 10^{8}$ & $\mathrm{~N} / \mathrm{m}$ \\
Total yield strength (Fy) & $4.00 \times 10^{6}$ & $\mathrm{~N}$ \\
\hline
\end{tabular}

Systems in which the centre of mass, $C_{\mathrm{M}}$, does not coincide with the centre of stiffness/strength experience torsional response in addition to pure translation. The centre of stiffness, $C_{\mathrm{R}}$, is defined as the location where if a lateral load is applied, in the elastic range of behaviour the system does not twist. The centre of strength, $C \mathrm{v}$, is defined as the location where if a lateral load is applied to the system, there is no torsional moment on the system in the inelastic range of behaviour [16]. The stiffness eccentricity, $e_{\mathrm{R}}$, and the strength eccentricity, $e_{\mathrm{V}}$, are defined as the distance between $C_{\mathrm{M}}$ and $C_{\mathrm{R}}$ and $C_{\mathrm{V}}$ respectively.

The second stage, considers a single-storey structure with strength/stiffness eccentricity to investigate the effect of hysteretic models on seismic response of torsionally irregular systems. The stiffness and its companion strength eccentricities are $e_{\mathrm{R}}=0.15 \mathrm{~L}$ and $e_{\mathrm{V}}=0.1 \mathrm{~L}$ respectively (Figure $3)$. The stiffness/strength eccentricity for the excitation in the $y$ direction is introduced by assigning larger stiffness and strength to the right hand side SFRS. However, the system is still symmetric in the $x$ direction.

The stiffness and strength eccentricities for the excitation in the $y$ direction can be found using Equation ((2) and ((3) respectively.

$$
\begin{gathered}
e_{R}=\frac{\sum x_{i} k_{i}}{\sum k_{i}} \\
e_{V}=\frac{\sum x_{i} V_{i}}{\sum V_{i}}
\end{gathered}
$$

where $\quad x_{\mathrm{i}}=$ distance of the element $i$ from $C_{\mathrm{M}}$ in the $x$ direction;

$k_{\mathrm{i}}=$ stiffness of element $i$ in the $y$ direction;

$V_{\mathrm{i}}=$ strength of element $i$ in the $y$ direction.

Mass rotational inertia, $I_{\text {rot }}$, is defined as the required torsion to cause a unit angular acceleration and can be found about centre of mass using Equation ((4).

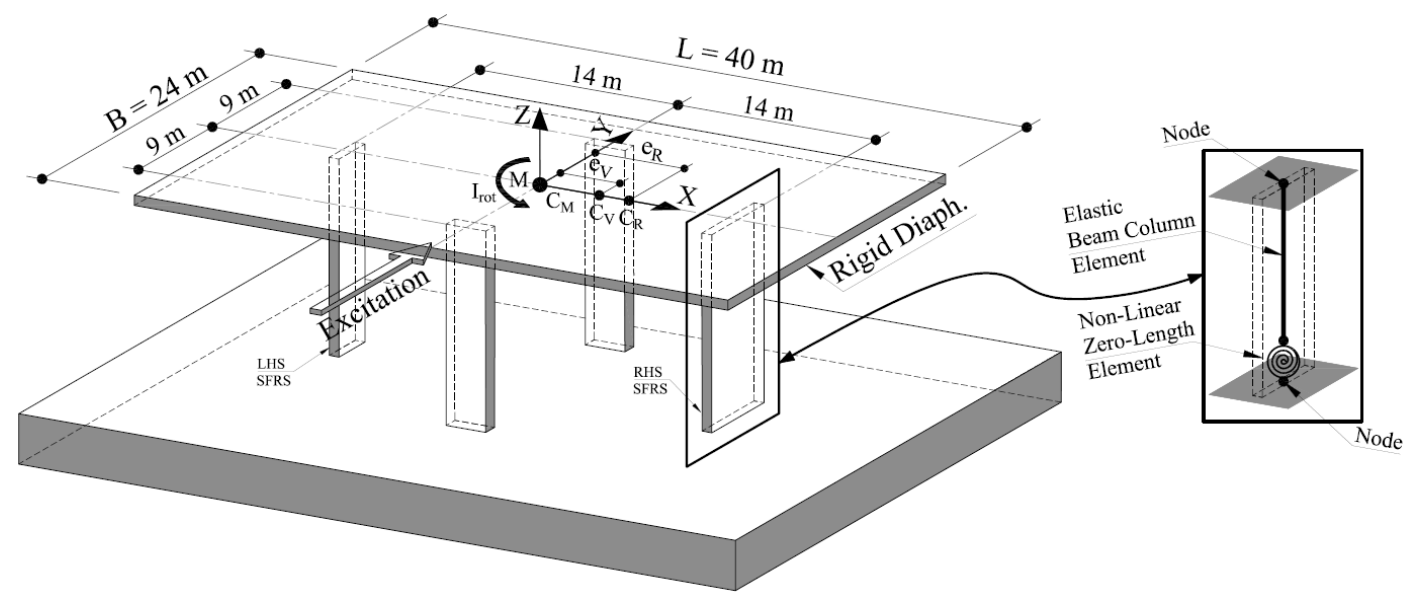

Figure 3: Schematic 3D view of the case study structure. 


$$
I_{r o t}=\int r^{2} d m
$$

where $\quad d m=$ infinitesimal mass;

$r=$ polar distance of the $d m$ from the centre of mass.

Assuming the $M$ is uniformly distributed over the plan, $I_{\text {rot }}$ of a rectangular plan can be simplified as shown below.

$$
I_{r o t}=M \frac{B^{2}+L^{2}}{12}
$$

The total translational stiffness and strength of the system in both directions are identical. The torsional stiffness of a structure in which all SFRSs are placed at distance of $d_{\mathrm{x}}$ and $d_{\mathrm{y}}$ from $C_{\mathrm{M}}$ in the $x$ and $y$ directions respectively, can be calculated using Equation ((6).

$$
K_{r o t}=\left[K_{i} \times\left(d_{x}{ }^{2}-e_{R x}{ }^{2}\right)\right]+\left[K_{i} \times\left(d_{y}{ }^{2}-e_{R y}{ }^{2}\right)\right]
$$

Please note that the eccentricity for the excitation in the $x$ direction, $e_{\mathrm{Ry}}$, is zero in Figure 3.

The configuration shown in Figure 3 results in a system with an uncoupled torsional to translational natural frequency ratio, $\Omega_{0}$, of 1.23 . The $\Omega_{0}$ is defined as $\omega_{\theta} / \omega_{\mathrm{y}}$ [17]. The $\omega_{\theta}$ and $\omega_{\mathrm{y}}$ are the uncoupled torsional $\left(\left[K_{\mathrm{rot}, \mathrm{CM}} / I_{\mathrm{rot}}\right]^{0.5}\right)$ and translational $\left(\left[K_{\mathrm{i}} / M\right]^{0.5}\right.$ ) natural frequencies respectively. The $K_{\mathrm{rot}, \mathrm{CM}}$ is calculated about the centre of mass to keep $\Omega_{0}$ independent of the eccentricity of the system. The parameters that define the torsional irregularity in the single-storey system are listed in Table 2 .

Table 2: Parameters to define the torsional irregularity.

\begin{tabular}{lcl} 
Parameter & Value & Unit \\
\hline Strength eccentricity $\left(e_{\mathrm{V}}\right)$ & 4.00 & $\mathrm{~m}$ \\
Stiffness eccentricity $\left(e_{\mathrm{R}}\right)$ & 6.00 & $\mathrm{~m}$ \\
Mass rotational inertia $\left(I_{\text {rot }}\right)$ & $7.25 \times 10^{8}$ & $\mathrm{~N} . \mathrm{s}^{2} . \mathrm{m}\left(\right.$ i.e. kg.m $\left.{ }^{2}\right)$ \\
Rotational stiffness $\left(K_{\mathrm{rot}}\right)$ & $3.81 \times 10^{10}$ & N.m \\
\hline
\end{tabular}

\section{Hysteretic Models}

For systems under strong earthquake shaking, the force demand may exceed the system yield strength, $F_{\mathrm{y}}$, and from then on the unloading and loading characteristic of the system are needed in addition to its initial stiffness (i.e. period of vibration) and damping to evaluate the seismic response. Five different hysteretic models are employed in this study as described in Figure 4 and Table 3.

The first model is elastic-perfectly-plastic (EPP). It is characterized just by an initial stiffness, $k_{\mathrm{i}}$, and yield strength, $F_{\mathrm{y}}$. EPP is the simplest model and assumes the same loading and unloading stiffness without incorporation of deterioration or strain hardening. The EPP model has characteristics that represent some isolation systems and some structural systems with friction connections [18]. The second hysteretic model is bilinear, which is similar to EPP except that strain hardening is incorporated in this model. The post-yield stiffness ratio of $r=0.05$ is assigned. The bilinear model with different values for $r$ represent the response of steel structures and lead-rubber bearing type of base-isolated systems [11]. The Takeda model is commonly used to represent the behaviour of reinforced concrete structures [19]. $\alpha$ and $\beta$ are the parameters defining the unloading and reloading characteristic of Takeda model. Structural systems with pinching characteristics such as reinforced concrete structures that are not detailed properly for ductile behaviour can be represented using the SINA model [20]. The SINA loop suffers from significant stiffness deterioration as the displacement demand increases. The SINA model is simplified in this work to have a bilinear instead its original trilinear backbone curve. The last hysteretic model is flag-shaped which has an unloading stiffness the same as the initial stiffness. However, after the lateral force during unloading decreases by $\beta_{\mathrm{f}} F_{\mathrm{y}}$ the displacement reduces to that from initial elastic curve following the post-elastic slope. Flagshaped hysteretic model can be representative of some posttensioned or self-centring systems.

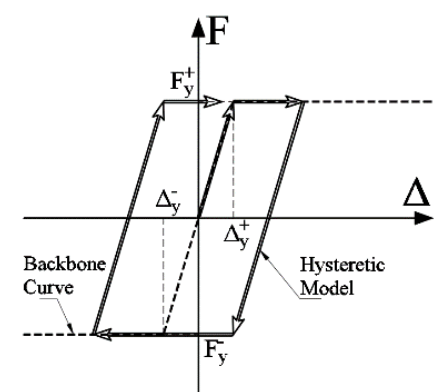

(a)

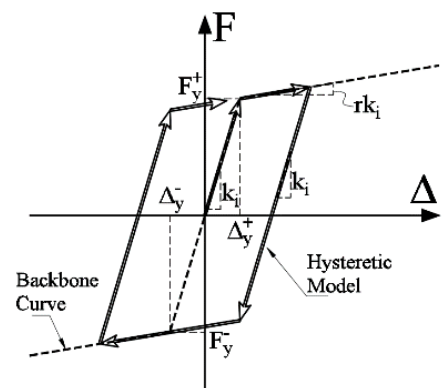

(b)

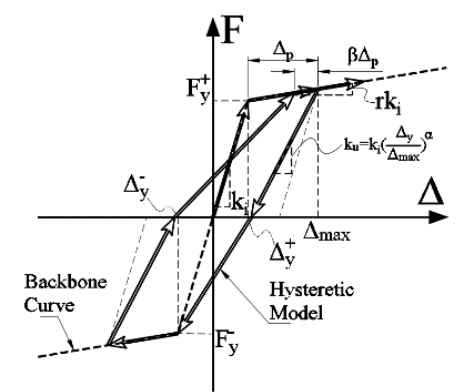

(c)

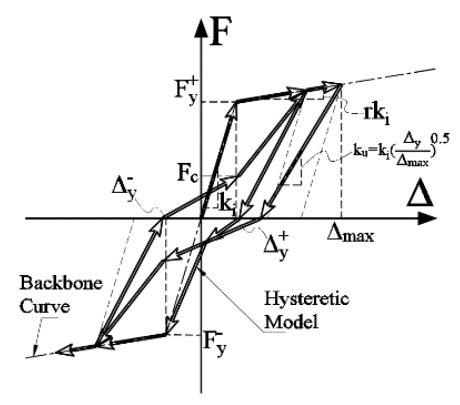

(d)

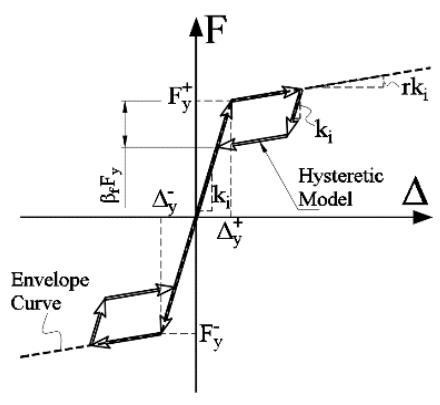

(e)

Figure 4: Hysteretic models: (a) EPP; (b) Bilinear; (c) Takeda; (d) SINA; (e) Flag-shaped. 
Table 3: Hysteretic behaviour parameters.

\begin{tabular}{ll} 
Hysteretic Model & Parameters \\
\hline Elastic-perfectly-plastic & $k_{\mathrm{i}}, F_{\mathrm{y}}$, \\
Bilinear & $k_{\mathrm{i}}, F_{\mathrm{y}}, r=0.05$ \\
Takeda (thin) & $k_{\mathrm{i}}, F_{\mathrm{y}}, r=0.05, \alpha=0.5, \beta=0$. \\
SINA & $k_{\mathrm{i}}, F_{\mathrm{y}}, r=0.05, F_{\mathrm{c}}=0.3 F_{\mathrm{y}}$ \\
Flag-shaped & $k_{\mathrm{i}}, F_{\mathrm{y}}, r=0.05, \beta_{\mathrm{f}}=0.5$ \\
\hline
\end{tabular}

OpenSees [21] is used to perform the NTHA using Newmark integration scheme with integration time step of $d_{\mathrm{t}}=0.01 \mathrm{~s}$. The equivalent viscous damping of $5 \%$ for the translational mode of vibration is assigned and a tangent stiffness proportional model is used. The mass proportional damping coefficient is ignored to have a more realistic estimation of damping of the system as discussed by Priestley et al. [11] for structures with few degrees of freedom. Analyses are conducted using a small displacement analysis regime, with mass and elements as shown in Figure 3, so $P-\Delta$ effects are ignored.

\section{Loading}

For the first part of the study, an impulse load is applied to the structure as shown in Figure 5 and Equation (7).

$$
I=F_{0} \times \Delta t=1.73 \times 10^{8}(N) \times 0.01(s)=1.73 \times 10^{6} N . s
$$

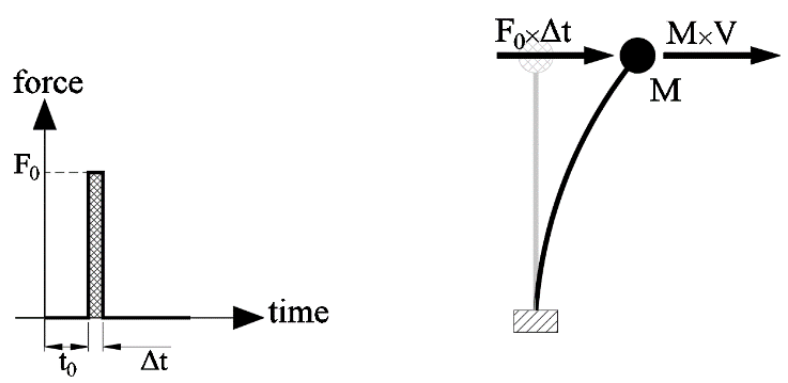

Figure 5: Impulse load applied to structure.

The impulse load is considered in this study because it helps to simply understand the key features of the seismic response of inelastic systems and chosen such that it pushes the SDOF systems to a displacement corresponding to $\mu=4$.

The impulse, $I$, causes momentum, $M \times V$, and the velocity, $V$, as shown in Equation (8).

$$
V=\frac{F_{0} \times \Delta t}{M}=\frac{1.73 \times 10^{6}(\mathrm{~N} . \mathrm{s})}{4.00 \times 10^{6}\left(\mathrm{~N} . \mathrm{s}^{2} / \mathrm{m}\right)}=0.434 \mathrm{~m} / \mathrm{s}
$$

where $\quad F_{0}=$ constant load over a short time period of $\Delta \mathrm{t}$.

For the NTHA, three ground motions are selected and shown in Figure 6. The first one, 1979 Coyote Lake earthquake recorded at the Gilroy Array Station 6, is representative of a short-duration impulse-type ground shaking, which is characteristic of near-field earthquake shakings (Figure 6(a)). The 5-75\% significant duration, $D_{\mathrm{S} 575}$ [22], of this ground motion is just less than $0.9 \mathrm{~s}$. The next two ground motions are two components of 1992 Landers earthquake recorded at Indio-Coachella Canal, California (Figure 6(b) and (c)). They can be considered more as long-duration cyclic-type ground motions. The $5-75 \%$ significant duration, $D_{\mathrm{S} 575}$, of these ground motions are about $25 \mathrm{~s}$. The latter ground motions are typical of far-field earthquakes.

These three ground motions are selected from a suite of 20 ground motion pairs for the purpose of NTHA in this work. The ground motion records are selected performing a probabilistic seismic hazard analysis as part of Project 17137 of Flagship 4 of QuakeCoRE for the subsoil class $C$ in Wellington, New Zealand and scaled for several hazard levels [23]. The set, with $10 \%$ probability of exceedance in 50 years, matches the spectral acceleration at a period of $1 \mathrm{~s}$.

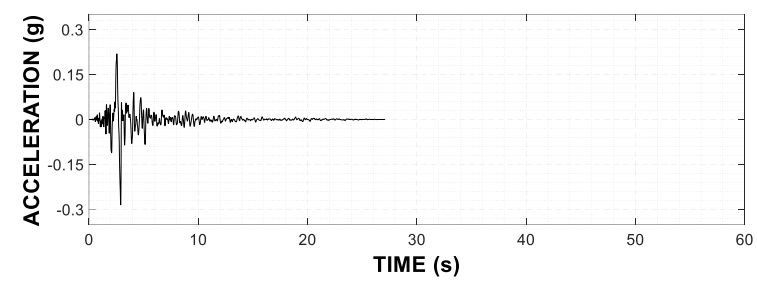

(a) 1979 Coyote Lake, Gilroy Array Station 6 - Component 230.

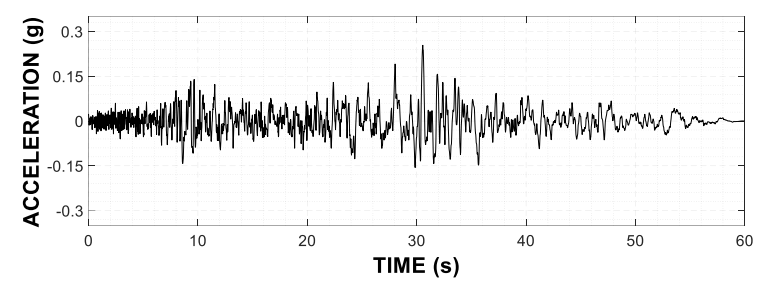

(b) 1992 Landers, Indio-Coachella Canal - Component 90.

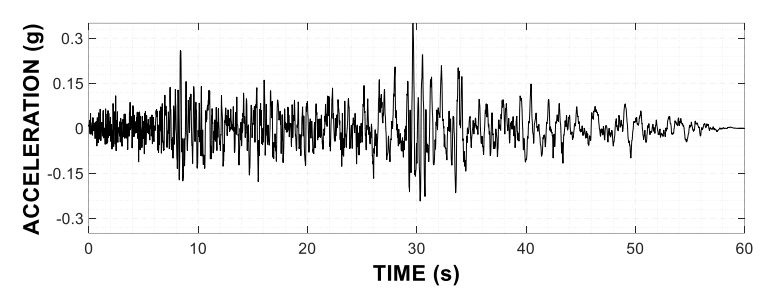

(c) 1992 Landers, Indio-Coachella Canal -Component 00.

Figure 6: Ground motions used for time-history analyses.

The impulse load and ground motion records are all selected and/or scaled to push the systems used in this study to displacements corresponding to a system ductility demand, $\mu$, of about 4. This value was large enough to reveal the difference in response for different hysteretic models.

\section{SDOF SYSTEM RESPONSE CONSIDERATIONS}

\section{Oscillators under Impulse Loading}

The backbone curve of bilinear, Takeda, SINA, and flagshaped loops, shown in Figure 4 and Table 3, are the same. The EPP loop has the same initial stiffness and yield strength as others without any post-yield stiffness. Therefore, the monotonic loading energy; the area under the monotonic loading curve above the zero force line (the shaded area in Figure 7); for bilinear, Takeda, SINA and flag-shaped are the same if the system is pushed to the same peak displacement. However, as can be seen in Figure 4 this area is smaller for EPP than for others.

Impulse loading (Figure 5) imparts an energy to the system, which is equal to the system kinetic energy, $E_{\mathrm{K}}$, as follows:

$$
E_{K}=\frac{1}{2} M \times V^{2}=\frac{1}{2} 4.00 \times 10^{6} \times 0.434^{2}=3.76 \times 10^{5} \mathrm{~N} . \mathrm{m}
$$

If a system is able to dissipate and/or store the input energy, it does not fail. The monotonic loading energy of the system, $E_{\mathrm{m}}$, which is sum of dissipated and potential energy of the system is equal to the input energy if the damping energy is ignored. To exclude the damping energy, the damping ratio, $\xi$, is set to zero. In Figure 7(a) to (e), the shaded areas, $E_{\mathrm{m}}$, are the same for all loops and equal to $3.76 \times 10^{5} \mathrm{~N} . \mathrm{m}$. In the figures in this 


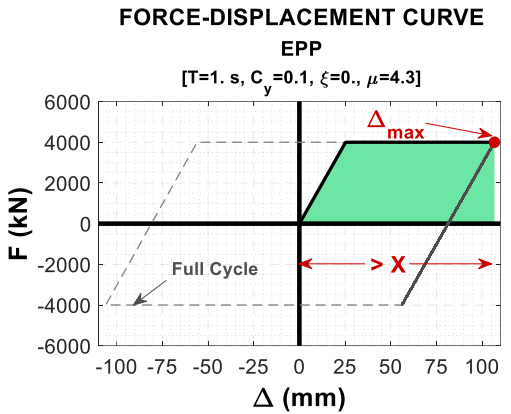

(a)

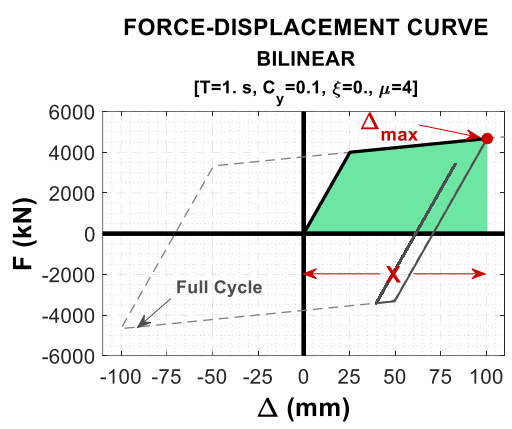

(b)

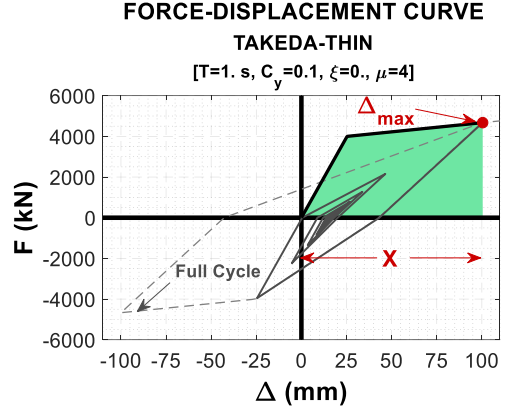

(c)

FORCE-DISPLACEMENT CURVE SINA

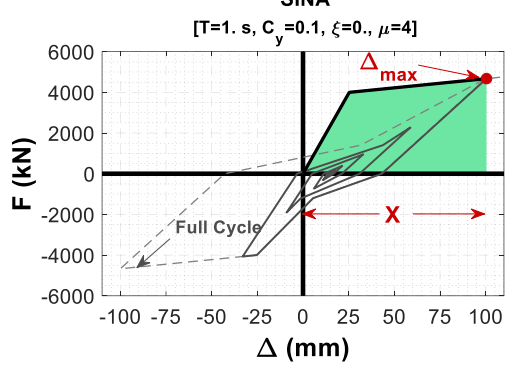

(d)

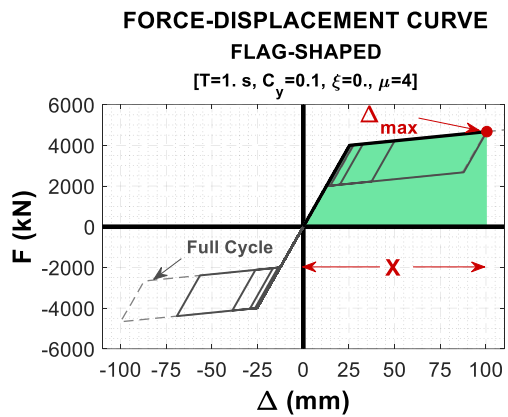

(e)

Figure 7: Response of SDOF system to impulse load: (a) EPP; (b) Bilinear; (c) Takeda; (d) SINA; (e) Flag-shaped. The monotonic loading energy is shown shaded.

paper, $F$ and $\Delta$ are the lateral force and lateral displacement of the system respectively.

Hysteretic loops with the same backbone curves shown in Figure 7(b) to (e) go to the same peak displacement (i.e. the same ductility, $\mu$ ) when subjected to impulse load shown in Equation (7) and Figure 5. Similarly, flag-shaped system with different $\beta_{\mathrm{f}}$ values (i.e. different flag sizes) experience the same peak displacement since regardless of the flag size, $E_{\mathrm{m}}$ is the same for flag-shaped loops with different $\beta_{\mathrm{f}}$ values. $\beta_{\mathrm{f}}$ just changes the proportion of the dissipated and the potential energy. However, to dissipate the same amount of energy, larger displacements in the initial direction may occur for EPP loops than for others as shown in Figure 7(a) because it has no post-yield stiffness. The displacement of the EPP system is $107 \mathrm{~mm}$ while those of others are $100 \mathrm{~mm}$.

\section{Unloading Behaviour of the Oscillators}

As discussed, for structures with the same backbone curve under one strong shake impulse, the response in the initial direction is identical and the systems have the same peak displacement as was seen in Figure 7. However, the total absolute response of the system may be affected by the unloading response, which causes displacement in the reverse (negative) direction. If damping and further shaking after the peak displacement are ignored, the tendency from the hysteresis curve itself to have a large displacement in the opposite direction may be obtained from consideration of the release of potential energy. The potential energy stored in the system is able to push the system back towards the negative direction.

The area within the hysteretic loop is the energy dissipated by yielding (the green areas in Figure 9). The green plus red area, monotonic loading energy, is the energy required to reach the peak displacement. The area above the horizontal axis and below the unloading path of the hysteretic response is the recoverable strain energy stored in the system (the red areas in Figure 9) [24]. When the system is released from a peak displacement, (the green circles in Figure 9) and permitted to oscillate, then the potential energy of the structure is the same as the recoverable energy. When the structure moves back to zero force (the red circles in Figure 9), then the potential energy is converted totally into kinetic energy. The momentum at this point causes the same amount of energy to enter the structure towards the opposite direction as shown by blue areas in the Figure 9.

The amount of potential energy stored in the system and the displacement of the system in the reverse direction are a function of hysteretic unloading and reloading characteristics respectively. It may be seen that the displacement toward the negative direction is larger for the Takeda, SINA, and flagshaped loops in the reverse loading half cycle than for the bilinear and EPP loops. That is because in the Takeda, SINA and flag-shaped loops, less energy is dissipated and a greater amount of energy is stored in the monotonic direction as compared to the bilinear and EPP loops. The stored energy can be interpreted as the larger potential to permit the system to displace in the reverse direction. Also the reloading stiffness of Takeda and SINA loops are smaller than that of others that results in larger movement towards the opposite direction. In addition, the displacement in the negative direction from the flag-shaped loop with $\beta_{\mathrm{f}}=0.5$ is still greater, as shown in Figure 9(e). With smaller flag size (i.e. smaller $\beta_{\mathrm{f}}$ and smaller energy dissipation when loaded to the same displacement) and larger potential energy stored in the system, the tendency of the flag-shaped loop to displace further in the negative direction increases.

In all cases in Figure 9, for an oscillator under a strong initial pulse-type motion, the displacement of the bilinear, Takeda, SINA and flag-shaped loops is the same in the initial (positive) loading direction and the peak displacement in the negative direction due to free vibration is less than that in the positive direction. For many structural systems used in practice, even when considering further earthquake shaking, the peak displacement in the negative direction may not exceed the peak displacement in the positive direction unless the energy dissipation capacity of the system (i.e. green areas in Figure 9) is small (e.g. flag-shaped with small $\beta_{\mathrm{f}}$ ). This is consistent with 
the EDA, which indicates that the peak displacement of a structure is only dependent on the initial loading characteristics of the hysteresis curve, and it has been formulated based on initial stiffness. It is also contrary to the secant stiffness assumption and it may be one reason that in general why the hysteretic energy is not always directly related to the energy dissipated by one complete displacement cycle of a hysteresis loop.

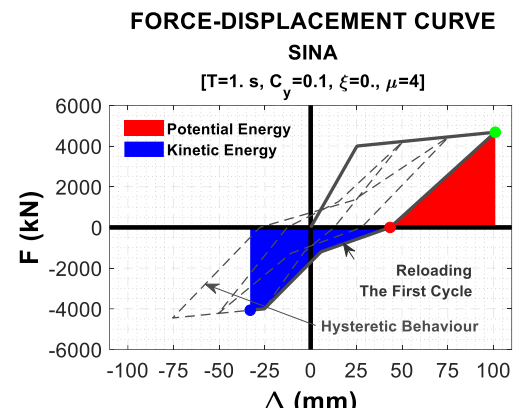

(a)

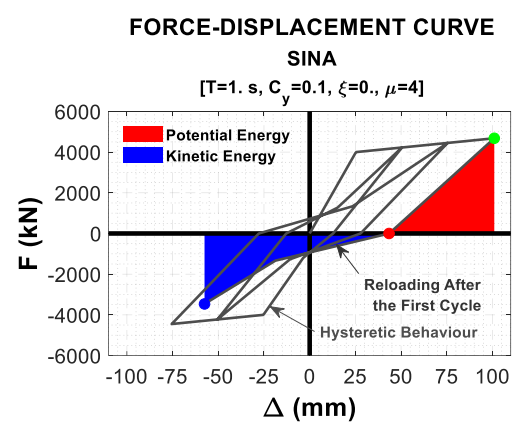

(b)

Figure 8: Unloading response of SINA hysteretic model after loading to a peak displacement: (a) The first cycle; (b) Cycles after the first cycle.
However, for general hysteresis loops, especially those with little energy dissipated, actual post-peak shaking can change the unloading response. When it increases the response in the negative direction, it may be seen that much less shaking effort is required for the flag-shaped loop to obtain a larger displacement in the negative direction (and hence a larger absolute displacement) than the other loops.

As may be seen in Figure 8, if a cycle has already occurred in the Takeda and SINA loops, the loading stiffness in the negative direction is even lower and causes a greater negative displacement. Therefore, the unloading effect causes its greatest effect not on the first loading half cycle, but in a subsequent half-cycle.

\section{Illustrating the Response of SDOF Systems to Impulse- Type Earthquake Records}

Analyses of SDOF systems with different hysteretic models subjected to the 1979 Coyote Lake - Gilroy Array \#6 with strong pulse characteristics (Figure 6(a)) are conducted. Figure 10 shows the response history of the systems with EPP, bilinear, and SINA obtained from NTHA. It can be seen that the maximum displacement occurs under the main impulse and the response follows the initial backbone curve for all systems. All the shaded areas in Figure 10 are identical irrespective of hysteretic behaviour. In addition, the maximum displacement is the same for all hysteresis loops with the same backbone curve (e.g. bilinear and SINA) irrespective of the unloading characteristics as shown in Figure 10(b) and (c). The maximum displacements for Takeda and flag-shaped with large flag size (e.g. $\beta=0.5$ ) models, which are not shown here for the sake of brevity, are exactly the same as those of bilinear and SINA. However, for flag-shaped model with very small $\beta_{\mathrm{f}}$, the absolute maximum displacement may be larger in the negative direction after the system is pushed to the absolute maximum displacement in the positive direction. Because the potential energy in the flag-shaped loop with small flag size is large and along with further energy input from ground shaking may push the system back to larger displacements in the negative direction. $\Delta_{\max }$ is $100 \mathrm{~mm}$ for all hysteretic models

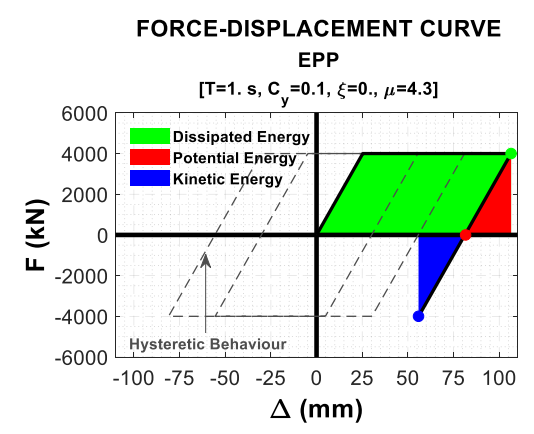

(a)

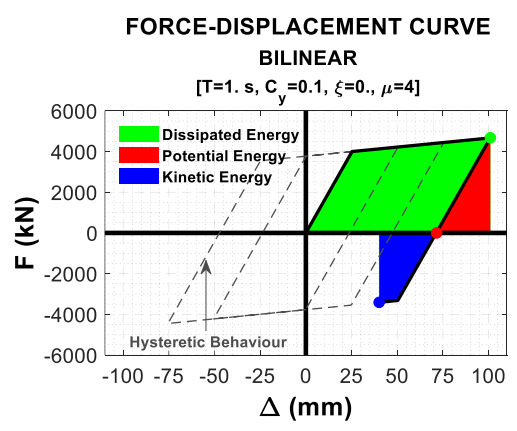

(b)

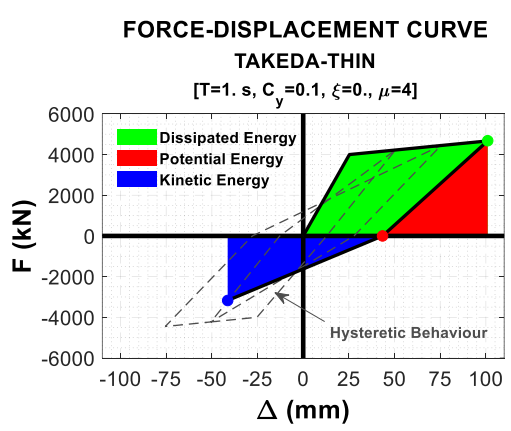

(c)

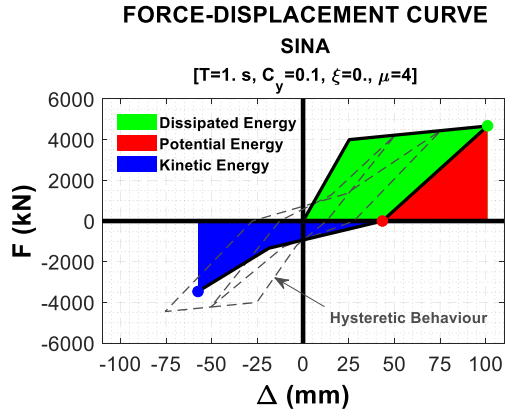

(d)

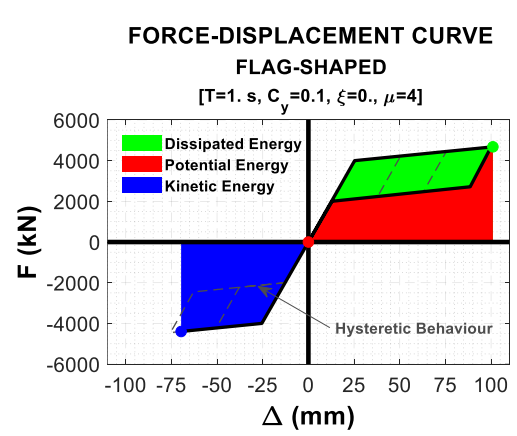

(e)

Figure 9: Unloading response of structure after loading to the same peak displacement: (a) EPP; (b) Bilinear; (c) Takeda; (d) SINA; (e) Flag-shaped. The monotonic loading energy is shown shaded. 

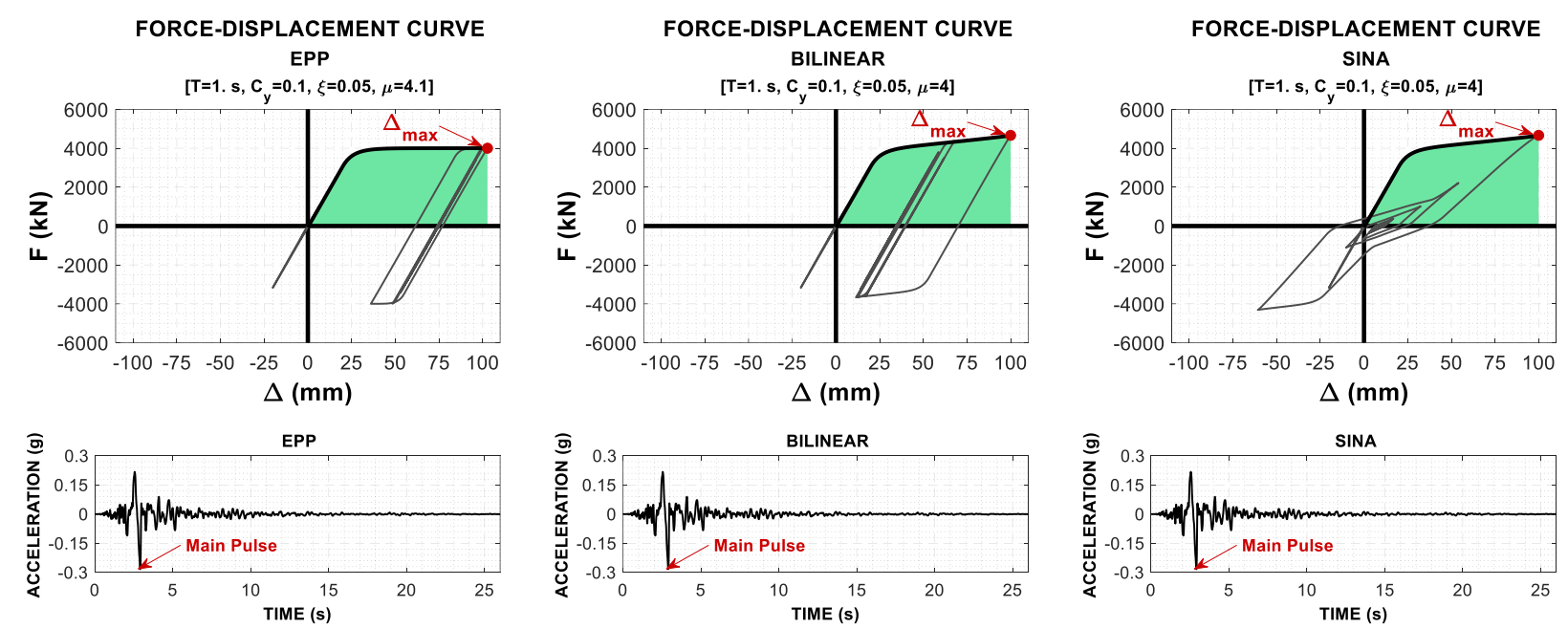

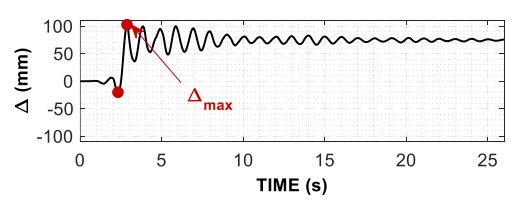

(a)

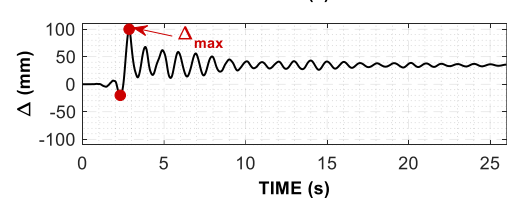

(b)

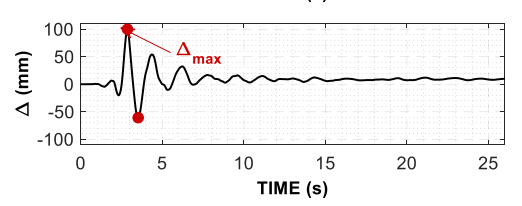

(c)

Figure 10: Response obtained from NTHA of a SDOF system subjected to 1979 Coyote Lake, Gilroy Array Station 6 Component 230: (a) EPP; (b) Bilinear; (c) SINA.

other than EPP. Loops with lower energy requirement to obtain the same displacement (e.g. EPP loop), have greater displacements (i.e. $\Delta_{\max }=103 \mathrm{~mm}$ ) when subject to the same motion as shown in Figure 10(a).

As was explained in the previous sections, the SINA loop, with smaller energy dissipation capacity, has a larger tendency to move back towards the negative direction. Therefore, after reaching the peak displacement in the positive direction, the energy stored in the system, the further energy imparted from shaking push it back to a larger absolute displacement in the reverse direction. However, since it never moves to the same absolute maximum displacement again in either direction, then the peak displacement is in the primary direction.

\section{Illustrating the Response of SDOF Systems to Long Duration Earthquake Records}

The systems examined in the previous section are now subjected to a relatively long-duration ground shaking record (1992 Landers, Indio-Coachella Canal - Component 90 (Figure 6)) in this section. Figure 11 shows that in general the peak displacements of structures increase with greater pinching. As shown in Figure 11 (f), systems with small $A_{\text {hyst }} / A_{\mathrm{m}}$ (please see Figure 2 ) are more pinched. Greater pinching causes an increase in displacement, which is consistent with the demand prediction based on the EVD methods. This is shown where the displacement generally increases with lower $A_{\text {hyst }} / A_{\mathrm{m}}$, at $\mu \approx 5$. The exception to this is the EPP structure response, where the recentering tendency of such loops is lower and cumulative displacements in one direction (ratcheting) can cause an increase in response [5]. In addition, for this particular earthquake record used in this work, SINA and flag-shaped loops do not follow the trend described above considering the EVD approach. As the displacement of SINA loop is smaller than flag-shaped (with $\left.\beta_{\mathrm{f}}=0.5\right)$ even though its $A_{\text {hyst }} / A_{\mathrm{m}}$ ratio is lower than flagshaped. For flag-shaped loop with small $\beta_{\mathrm{f}}$ values (i.e. small flag size), the energy dissipation capacity of the system, $A_{\text {hyst }} / A_{\mathrm{m}}$ shown in Figure 2, drops and the system experiences significantly larger displacements under a cyclic-type long duration ground shaking. On the other hand, the fact that the difference between these displacements is only $40 \%$ is representative of the accuracy of initial stiffness proportional methods, which consider that the displacement is not sensitive to hysteresis loop unloading characteristics.

When post-yield stiffness tended to become flat (i.e. EPP), there were greater displacements because of ratcheting where the structure no longer oscillated about its initial at-rest position [5]. The ratcheting of the EPP loop can be easily seen in Figure 12. For structures without a strong dynamic recentering tendency, the likelihood of ratcheting (i.e. continuing to yield mainly in one direction during multiple cycles of earthquake shaking) increases causing larger displacements [15]. This is particularly significant for hysteresis loops with low - or negative - bilinear stiffness ratio [5]. Such behaviour may occur because of member effects (such as material, or local buckling), or global effects (such as P-Delta, or structural form or eccentric gravity loading) and/or for those with different strengths in each direction. It is also more likely during long duration shaking [11].

The ratcheting effect is consistent with the analyses undertaken in this section. The SDOF system is subjected to 1992 Landers, Indio-Coachella Canal - Component 00, a long duration ground motion shown in Figure 6(c). Here, the peak displacement for the EPP structure is $218 \mathrm{~mm}$ that is greater for than those of others (i.e. $160 \mathrm{~mm}$ and $140 \mathrm{~mm}$ for Takeda and flag-shaped respectively). The peak displacement in the positive direction is much larger than that in the negative direction as the EPP model has no inherent tendency to go back towards the zero displacement position. With a greater tendency for displacement in the initial direction than the reverse direction, the displacement of EPP model accumulates in one direction. However, SINA and flag-shaped show larger recentering characteristics and oscillate about the zero displacement position. Because of the recentering characteristic of loops such as SINA and flag-shaped, they are more likely to move back towards their original position when they are pushed away from the original position. 


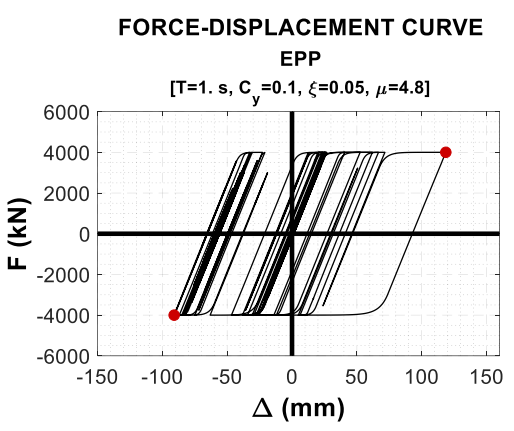

(a)

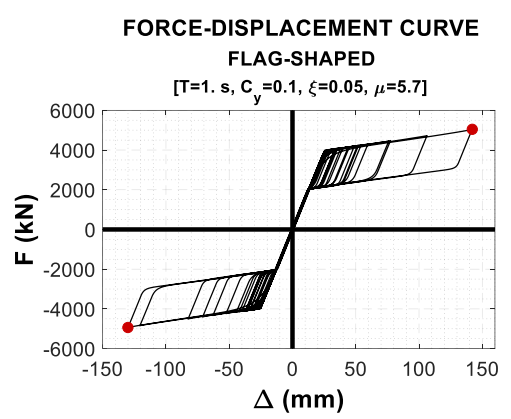

(d)

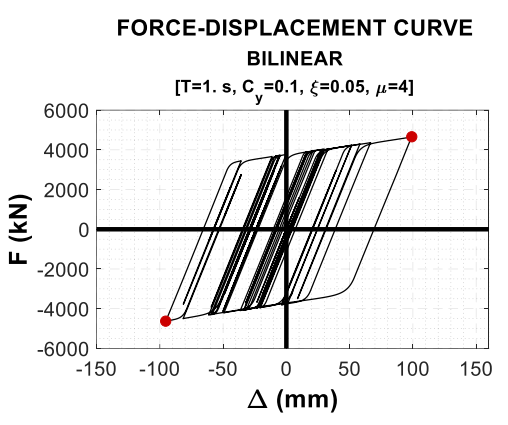

(b)

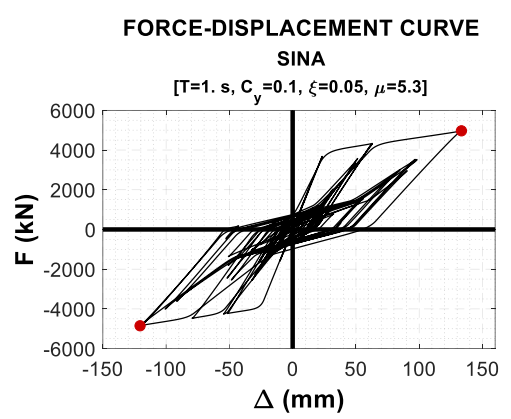

(e)

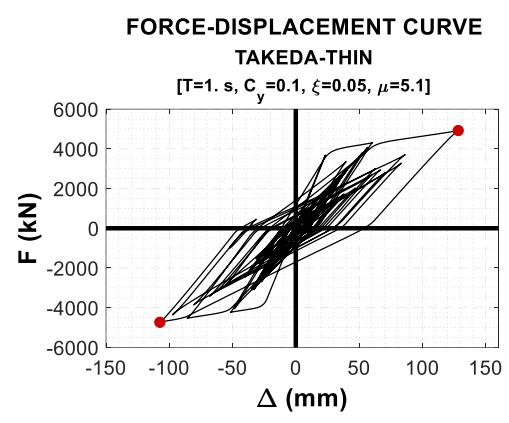

(c)

\begin{tabular}{lcc}
$\begin{array}{l}\text { Hysteretic } \\
\text { model }\end{array}$ & $\begin{array}{c}\frac{\boldsymbol{A}_{\text {hyst }}}{\boldsymbol{A}_{\boldsymbol{m}}} \\
(\boldsymbol{\mu = 5 )}\end{array}$ & $\begin{array}{c}\boldsymbol{\Delta}_{\max } \\
(\mathbf{m m})\end{array}$ \\
\hline EPP & 0.80 & 120 \\
Bilinear & 0.61 & 100 \\
Takeda & 0.22 & 130 \\
Flag-shaped & 0.15 & 145 \\
SINA & 0.13 & 135 \\
\hline
\end{tabular}

$(f)$

Figure 11: Response of structure to 1992 Landers, Indio-Coachella Canal-Component 90: (a) EPP; (b) Bilinear; (c) Takeda; (d) Flag-shaped; (e) SINA; (f) Area ratios and response.

This may also explain why Equation ( (1) predicts displacement of the pinched models better than fat ones [11]. Because EVD based methods assume that the system oscillates between two absolute maximum points in the positive and negative directions. The validity of this assumptions is highly dependent on the self-centring characteristic of the hysteretic behaviour and the earthquake record. For example, for Takeda and SINA models the system oscillates between the positive and negative directions significantly more that EPP and bilinear loops.
The ratcheting effect is not considered explicitly in either the initial stiffness-based or the area-based EVD methods. Therefore, both methods may be non-conservative for structures with a negative post-yield stiffness subjected to medium to long duration earthquakes [5]. Methods that have been calibrated to the results of NTHA, such as the calibrated EVD expressions in Pennucci et al. [25], will be more reliable but only if the ground motion characteristics used for calibration are similar to those expected at the site in question.
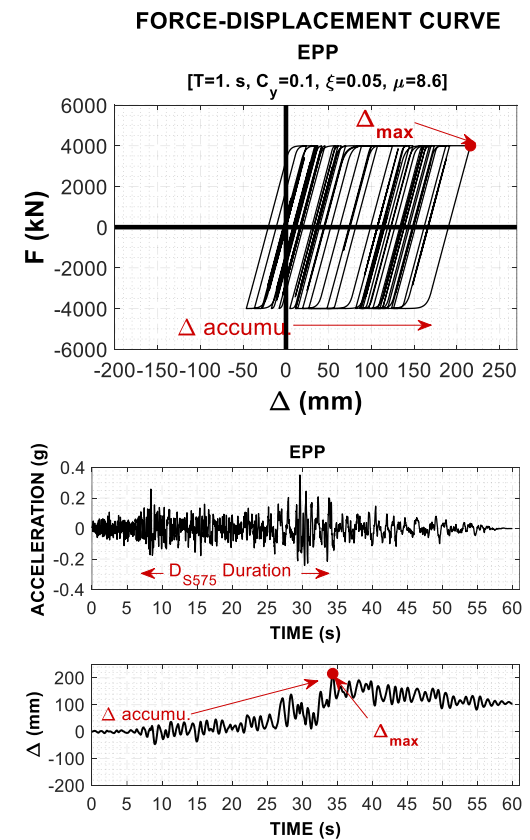

(a)

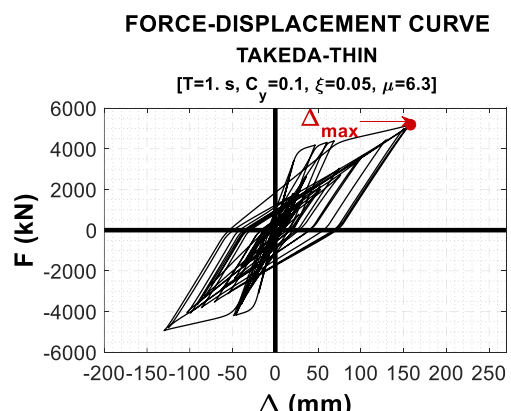

$\Delta(\mathrm{mm})$
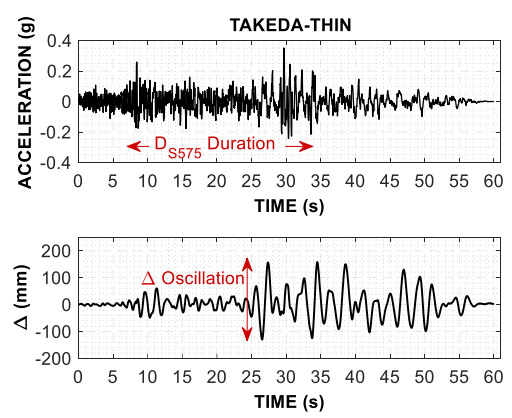

(b)
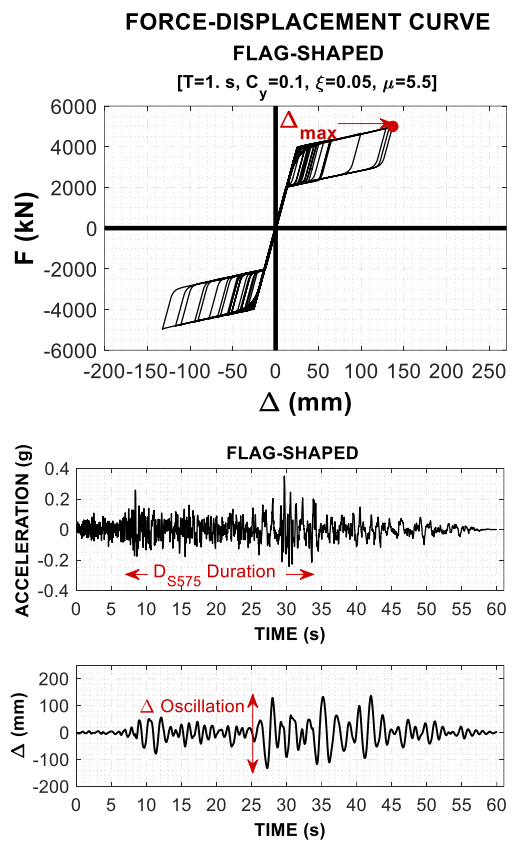

(c)

Figure 12: Ratcheting due to no post-yield stiffness subjected to 1992 Landers, Indio-Coachella Canal-Component 00: (a) EPP; (b) Takeda; (c) Flag-shaped. 


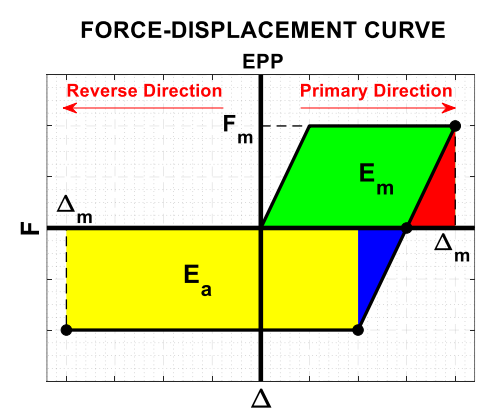

(a)

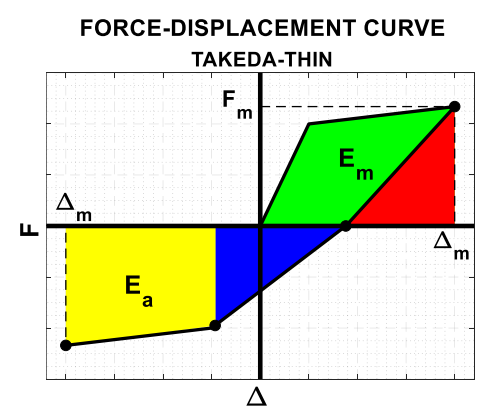

(b)

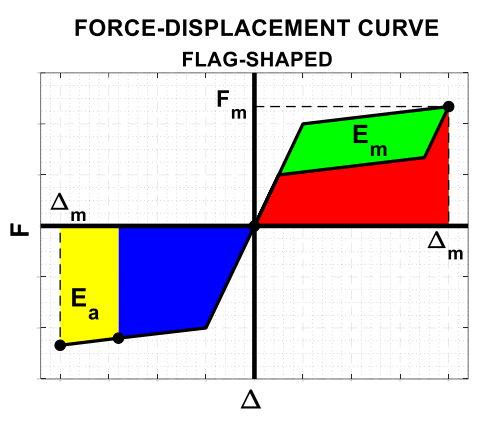

(c)

Figure 13: Definition of Ea: (a) EPP; (b) Takeda; (c) Flag-shaped.

\section{Oscillation Resistance Ratio, $O R R$}

The additional input energy required to cause a displacement of $\left|\Delta_{\mathrm{m}}\right|$ in the reverse direction, $E_{\mathrm{a}}$, is given as the yellow area in Figure 13. This energy represents a resistance to greater displacements in the reverse direction. Longer duration ground shaking may cause this resistance to be overcome resulting in increased peak absolute displacements. However, for any specific ground shaking as $E_{\mathrm{a}}$ decreases, displacement demand in the reverse direction tends to increase because the energy input required to cause bigger displacement in the reverse direction is less. The primary and reverse directions are defined as shown in Figure 13(a).

The additional input energy required to load the oscillator monotonicaly to the displacement of $\left|\Delta_{\mathrm{m}}\right|$ in the reverse direction, $E_{\mathrm{a}}$, may be normalised. The normalised $E_{a}$ may be termed an oscillation resistance ratio, ORR, as it is an indication of the resistance of the hysteretic loop to large inelastic oscillations in the reverse direction. This is consistent with the way larger displacement of EPP model in the primary direction than that of reverse direction shown in Figure 12 as the greater ORR means larger resistance to displacement in the reverse direction. While it may be normalized in a number of ways, two methods are given below. In both cases, the ORR is a function of the ductility demand of the oscillator.

1. $\mathrm{ORR}_{\mathrm{A}}$ is given in Equation (10), where $E_{\mathrm{a}}$ is the yellow area and $E_{\mathrm{m}}$, monotonic loading energy, is the sum of green and red areas in Figure 13. ORR $\mathrm{A}$ ranges between 0.0 for elastic systems and 1.0 for EPP systems with high ductility as illustrated in Figure 14.

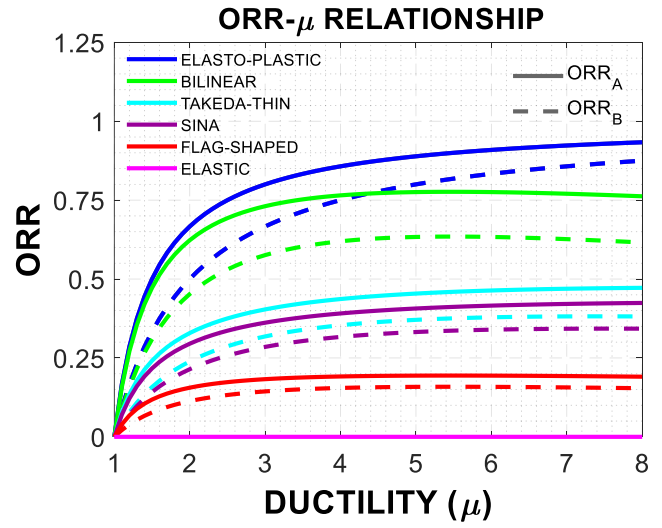

Figure 14: Effect of ductility on ORR.

2. ORRB may be given in Equation (11), where the terms in the denominator are $\Delta_{\mathrm{m}}$ from Figure 13 and $F_{\mathrm{m}}$ which is the peak force corresponding to loading to the monotonic displacement $\Delta_{\mathrm{m}}$. ORRB ranges between 0.0 for elastic systems and 1.0 for EPP systems with high ductility. The denominator is this case is simpler to compute than for ORRA.

$$
\begin{aligned}
& O R R_{A}=E_{a} /\left(2 E_{m}\right) \\
& O R_{B}=E_{a} /\left(2 F_{m} \Delta_{m}\right)
\end{aligned}
$$

This ORR, in addition to the duration of shaking described previously, influences the peak response. Both definitions of ORR as a function of $\mu$ for different hysteretic models are shown in Figure 14.

Some considerations about the peak absolute displacement, considering the ORR and the ground motion characteristics below:

- For an elastically responding structure the ORR is zero and there is a greater likelihood of oscillation in the reverse (negative) direction.

- For an EPP structure as shown in Figure 13(a), the ORR is high and it is unlikely that there will be a greater displacement in the reverse direction under short duration earthquake records. This is true when the period of the structure is long enough so the earthquake does not push it in the reverse direction. However, the displacement in the reverse directon may still increase if there are many cycles of loading on the structure. This is because it then behaves more like the substitute structure described by Gulkan and Sozen [9], Priestley [7] and others where the structure is modelled as having a stiffness equal to the secant stiffness, and the EVD is related to the energy dissipated. This could explain the adoption of different displacement prediction equations for short period structures in many building loadings standards (e.g. NZS1170.5 [15]) which indicate larger displacements than EDA values for oscillators with a period less than around $0.7 \mathrm{~s}$ on normal sites.

- For some stiffness degrading loops, such as the Takeda loop shown in Figure 13(b), $E_{\mathrm{a}}$ and the ORR decrease slightly with the number of cycles experienced due to stiffness degradation. This was also seen with the SINA loop in Figure 8.

- For a flag-shaped structure (Figure 13(c)), as the dissipative energy decreases, the ORR becomes closer to zero, increasing the likelihood of increased displacement in the reverse direction. However, for large energy dissipation capacities (i.e. large flag size), the ORR becomes close to that of SINA and Takeda models.

- For a bilinear loop, the ORR decreases with greater positive post-yield stiffness factor, $r$. When $r=1$, the behaviour is fully elastic the ORR $=0$ giving an increased likelihood for displacements in the reverse direction.

The ratio of the oscillator displacement in the reverse direction $\Delta_{\mathrm{rev}}$, to that in the primary direction $\Delta_{\max }, \Delta_{\mathrm{rev}} / \Delta_{\max }$, as a function of the ductility, $\mu$, is shown in Figure 16 and Figure 17 for a pure impulse loading with $\xi=0 \%$, and an impulse- 
type short duration record with $\xi=5 \%$ respectively, assuming different hysteresis loops. $\Delta_{\min }$ and $\Delta_{\max }$ are the minimum and maximum displacements, respectively. $\Delta_{\max }$ is the largest displacement in the primary direction which often happens under the main pulse and $\Delta_{\text {rev }}$ is the absolute largest displacement in the reverse direction right after $\Delta_{\max }$ as shown in Figure 15.

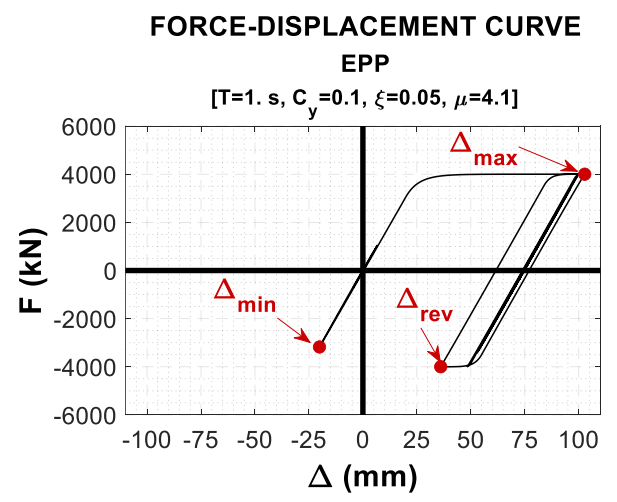

(a)

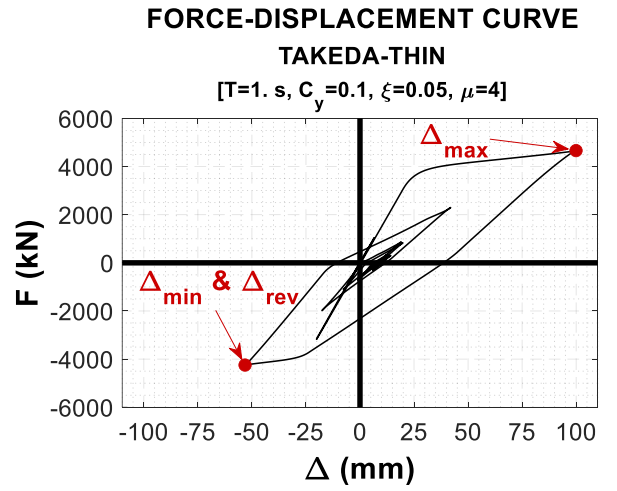

(b)

Figure 15: Definition of $\Delta_{\max }, \Delta \mathrm{min}$, and $\Delta_{r e v}$.

As was seen in Figure 14, ORR increases with increasing ductility. However, as the demand approachs the value associated with a ductility of about 3 , the ORR curves in Figure 14 start to reduce slope and become flat, so for greater ductilies, the ORR does not change much. ORR $\mathrm{B}_{\mathrm{B}}$ of about 0.15 , 0.30, 0.65 for flag-shaped, Takeda, and EPP loops respectively correspond approximately to a ductility of about 3 . The displacement ratio, $\Delta_{\mathrm{rev}} / \Delta_{\max }$, may be expected to be in a linear relationship with ORR $\mathrm{O}_{\mathrm{B}}$. This can be seen in Figure 16 (a) for a system under a pure impulse loading. However, for individual records, there may be significant variation depending on the record. This is seen in Figure 17(a) for the single impulse-type earthquake record used.

For large ORR (i.e. $\mu$ ), the oscillator does not tend to oscillate to large displacements in the reverse direction. Because of this, for a range of high $\mu,\left|\Delta_{\max } / \Delta_{\text {elastic }}\right|$, where $\Delta_{\text {elastic }}$ is the maximum displacement of the elastic structure with the same initial stiffness, does not change (For SDOF structures, $\Delta$ elastic is the same as the spectral displacement, $S_{\mathrm{d}}$ ). This results in the displacements of oscillators with significant energy dissipation being similar (Figure 17(b)). This is consistent with the equal displacement assumption in which displacement prediction is independent of the unloading characteristics of the hysteresis loop. However, for the system subjected to an impulse, the displacement in the primary direction is such that the monotonic loading energy, $E_{\mathrm{m}}$, of the system is equal to the total input energy. Therefore, as can be easily seen in Figure $16(\mathrm{~b}), \Delta_{\max } / \Delta_{\text {elastic }}$ is increasing as $O R R$ increases.

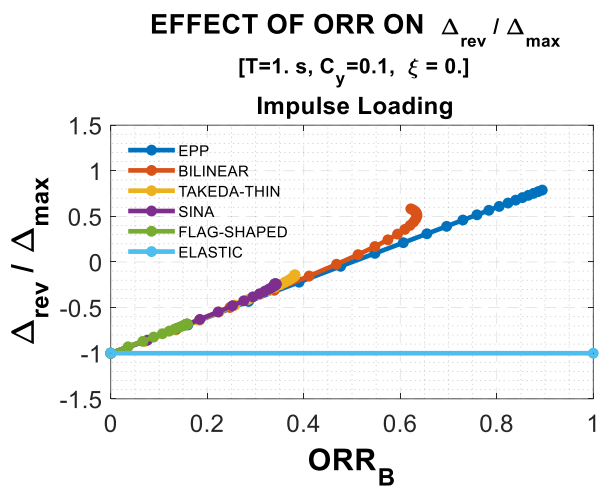

(a)

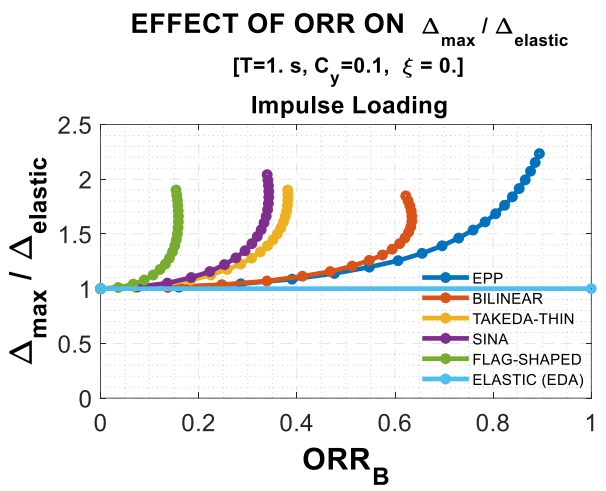

(b)

Figure 16: Effect of ORR on displacement amplification Pure impulse load.

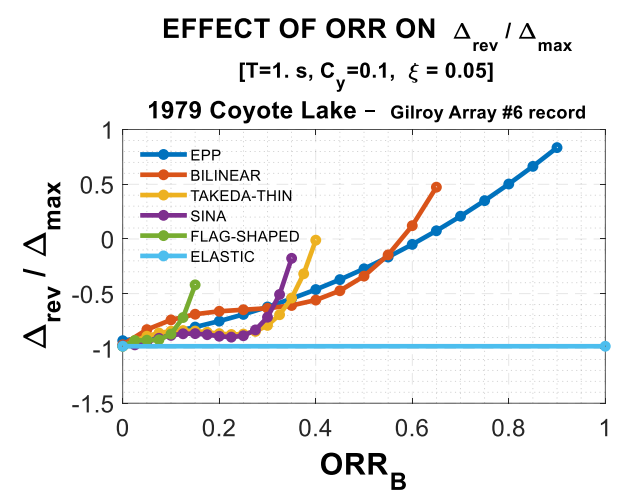

(a)

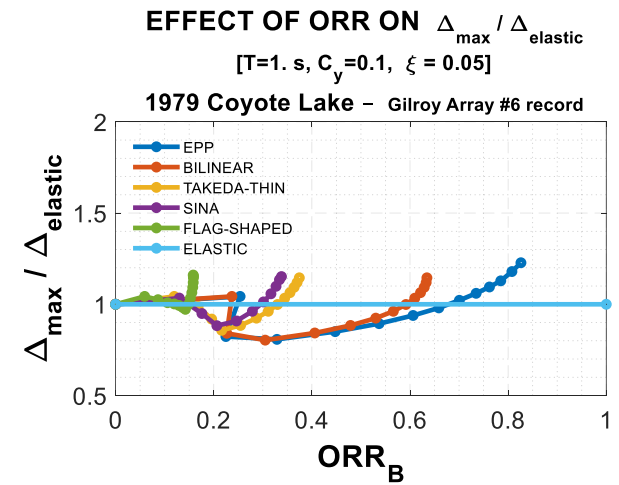

(b)

Figure 17: Effect of ORR on displacement amplification Impulse-type ground motion. 


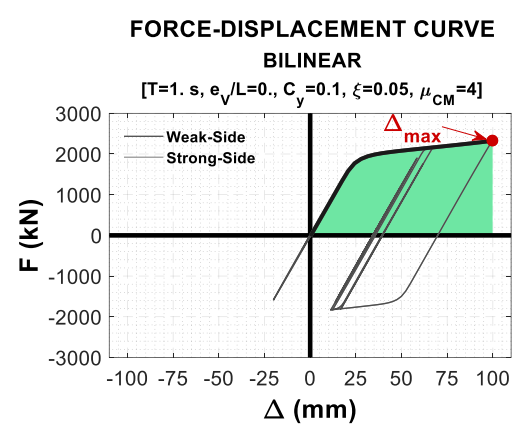

(a)

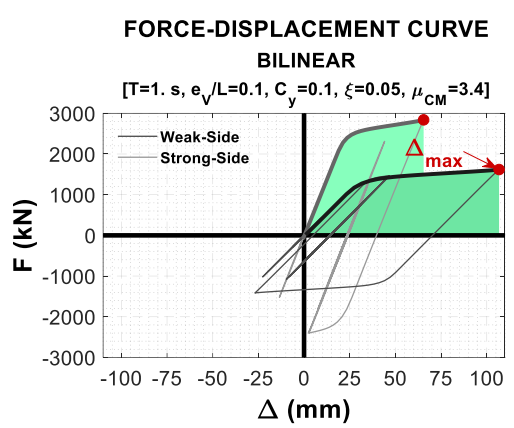

(b)

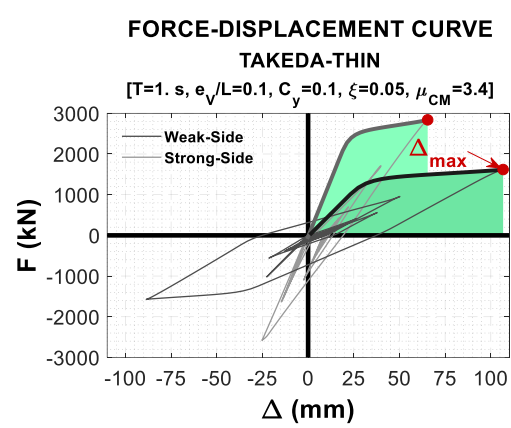

(c)

Figure 18: Response of single-storey systems with different hysteretic characteristic to 1979 Coyote Lake, Gilroy Array Station 6 Component 230: (a) Bilinear $-e_{V}=0$; (b) Bilinear $-e_{V} \neq 0$; (c) Takeda $-e_{V} \neq 0$.

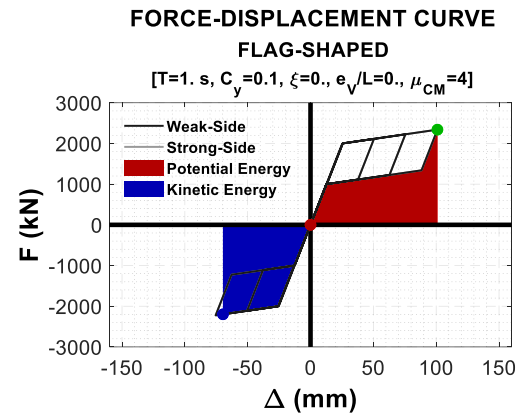

(a)

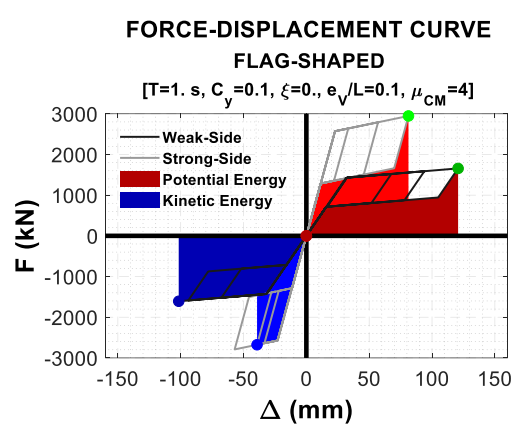

(b)

Figure 19: Unloading response of system with and without torsional irregularity after loading to the peak displacement: (a) Flag-shaped $-e_{V}=0$; (b) Flag-shaped $-e_{V} \neq 0$.

\section{TORSIONAL CONSIDERATION}

The considerations above relate to structures where torsional effects are not significant. Systems with stiffness and/or strength eccentricities $\left(e_{\mathrm{V}} \neq 0\right)$ under impulse-type ground shaking experience the same peak displacement when they have the same backbone curve as shown in Figure 18. This is a similar trend to that observed for structures without torsion. Analyses of systems with and without significant torsional irregularity $(e \mathrm{v} \neq 0)$ are shown for bilinear and SINA hysteresis loops with the same backbone curve to the 1979 Coyote Lake - Gilroy Array \#6 record component 230 (Figure 18(b) and (c)). The structural period in the direction of shaking is $1.0 \mathrm{~s}$ and the damping ratio is $5 \%$ as described in the methodology section.

However, for systems with torsional irregularity $\left(e_{v} \neq 0\right)$, the SFRS perpendicular to the direction of loading also absorb energy as the building twists. In general, the total earthquake input energy must enter the different elements. The energy taken by the out-of-plane elements reduces the energy input into other elements of the structure, such as those in the direction of loading, and this in turn reduces the average inplane system displacement compared to that of systems without torsion (Figure 18(a) and (b)). Because of this, the displacement of centre of mass is likely to be less for systems with torsional irregularity $(e v \neq 0)$ than if there were no torsion [26]. This decrease in centre of mass displacement for singlestorey systems (e.g. the system shown in Figure 3), for a range of $e \mathrm{v}$ (i.e. $0 \leq e \mathrm{v} / L \leq 0.2$ ) can be up to $25 \%$.

When a torsional structure with SFRS in the perpendicular direction (providing torsional restraint) has the centre of mass pushed to a certain displacement, the recoverable strain energy stored in the system increases compared to a system without any torsion. It may cause the element with the largest displacement in the direction of loading to undergo increased displacement in the reverse (negative) direction. This was seen in Figure 18(c) for the pinched loop compared to Figure 18(b). In addition, as can be seen in Figure 19, for the weaker element of the system, the ratio of the displacement in the negative direction to that in the positive direction is larger for the case of the systems with stiffness and strength eccentricities (Figure 19(b)) than for the systems without any torsion (Figure 19(a)). That is because the energy stored in out-of-plane elements was mainly used by the weaker element making it displace more in the negative direction.

Figure 20(a) shows the system without eccentricity described in the methodology section under the 1979 Coyote Lake Gilroy Array \#6 record (an impulse-type ground shaking). Obviously, the displacement is uniform over the plan and both sides of the plan reach to the same displacement. As discussed before, the system without eccentricity responds to the peak displacement under the first major impulse following its initial backbone curve and then it is less likely to get to an absolute displacement larger than the first peak, in the initial direction, in the opposite direction. However, in the system with eccentricity shown in Figure 20(b), ground shaking makes the system twist as well as translate. Under the first major impulse, both the weak and strong sides of the structure move to the peak displacement in the primary direction. In addition to the recoverable strain energy in the SFRS in the direction of loading, some amount of energy is stored in the SFRS of the perpendicular direction. When the system reaches the peak displacement in the primary direction, the extra energy imparted by the ground shaking along with the energy stored in the whole system are mainly mobilized to displace the weaker element in the reverse direction beyond its peak displacement in the positive direction. 


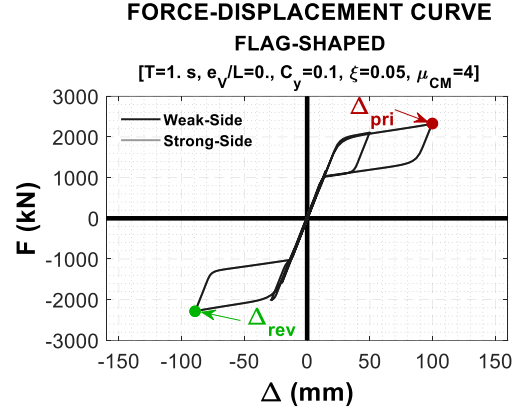

(a)

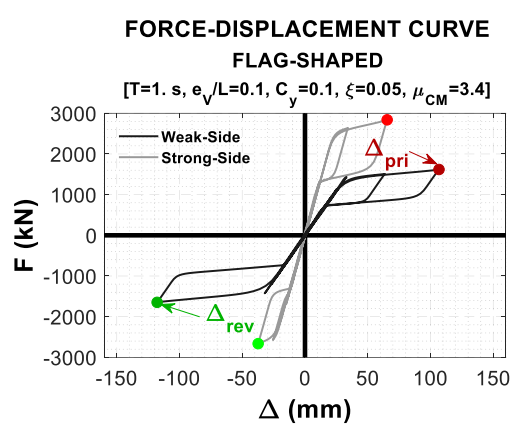

(b)

Figure 20: Response of single-storey system to 1979 Coyote Lake, Gilroy Array Station 6 - Component 230 (impulse-type ground motion): (a) Flag-shaped $-e_{V}=0$; (b) Flag-shaped $-e_{V} \neq 0$.

\section{CONCLUSIONS}

The response of single-storey system with different hysteretic models under impulse-type and long duration earthquake ground shaking is described. Five different hysteretic models are considered in this study and effects of hysteretic behaviour on seismic response of the system is explained using the energy approach. Analyses of systems with torsional response is carried out to explore the effects of hysteretic behaviour and ground motion characteristics on torsional response too. It was shown that:

1. For structural systems with the same backbone curve subject to impulse records, they achieved the same peak displacements. These peak displacements were significantly greater in one direction than in the other direction, since there was no additional input energy to cause large displacements in the reverse direction.

2. When the same structures were subject to actual earthquake records, the response depended on both the shaking duration, and the hysteresis loop shape. Actual records with very short duration, which acted like impulse records, gave similar behaviour to the impulse load, with the same peak displacement for oscillators with the same loading characteristics irrespective of the unloading characteristics. However, for long duration records, a significant oscillation occurred compared to short duration records, but this was more for hysteresis loops with low resistance to oscillation, such as pinched loops. For hysteresis loops like EPP (with larger resistance to oscillation), it was likely that the system ratchets and does not oscillate.

3. An oscillation resistance ratio (ORR) has been introduced as a characteristic of a hysteresis loop that quantifies, in energy terms, the unloading characteristics of different hysteretic systems. This ratio, together with the shaking duration affecting the structural period of interest, has been used to explain the general behaviour of structures with different hysteresis loops subject to different types of excitation. When structures are subject to short duration loading, the unloading characteristics (and hence ORR) should not be expected to affect the peak response significantly, supporting the use of common initial stiffness-based methods such as the equal displacement assumption. On the other hand, when ground motions are of longer duration, with more significant oscillations imposed the unloading characteristics (and hence differences in ORR) become more important. For those with high ORR the peak displacement for a certain spectral displacement are likely to be lower than for low ORR. Given these points, this work helps reconcile differences in different peak-displacement estimation methods such as substitute structure methods (with secant stiffness and equivalent viscous damping) and initial stiffness based methods. Since the seismic hazard at a site may be affected by both short and long duration ground shaking a single method may not be appropriate for all site events.

4. For systems with torsion in addition to translation, subjected to impulse-type earthquake records, the peak displacements occur during the first major pulse and they are the same value for all hysteretic models with the same monotonic loading properties. Since the lateral force resisting systems in the orthogonal direction store some energy imparted by earthquake shaking, the displacement of the centre of mass is smaller compared to its companion system without torsion. The energy stored in the out-ofplane seismic force resisting systems releases in the unloading phase of the response and, along with the energy imparted by the ground shaking, may cause the weaker element of the system to have larger displacement in the reverse direction. This indicates that considerations in the secondary direction are important to consider the torsion effect on structural displacement prediction.

\section{ACKNOWLEDGMENTS}

The authors wish to thank the anonymous reviewers for their detailed and insightful comments. The first author also wishes to thank the University of Canterbury for the UC Doctoral Scholarship.

\section{REFERENCES}

1 Veletsos S and Newmark N (1960). "Effect of inelastic behavior on the response of simple systems to earthquake motions". Proceedings of Second World Conference on Earthquake Engineering, Tokyo, Japan.

2 Newmark N and Hall W (1973). "Seismic Design Criteria for Nuclear Reactor Facilities". Report No. 46, Building Practices for Disaster Mitigation, National Bureau of Standards, US Department of Commerce.

3 Federal Emergency Management Agency (2000). "FEMA 356: Prestandard and Commentary for the Seismic Rehabilitation of Buildings". Prepared by ASCE for the Federal Emergency Management Agency, Washington, DC, 518pp.

4 Priestley MJN and Park R (1987). "Strength and ductility of concrete bridge columns under seismic loading". ACI Structural Journal, 84(1): 61-76.

5 MacRae GA (1994). "P- $\Delta$ effects on single-degree-offreedom structures in earthquakes". Earthquake Spectra, 10(3): 539-568. https://doi.org/10.1193/1.1585788

6 Miranda E and Bertero V (1994). "Evaluation of strength reduction factors for earthquake-resistant design". Earthquake Spectra, 10(2): 357-379. https://doi.org/10.1193/1.1585778 
7 Priestley MJN (1997). "Displacement-based seismic assessment of reinforced concrete buildings". Journal of Earthquake Engineering, 1(1): 157-192. https://www.worldscientific.com/doi/abs/10.1142/S13632 46997000088

8 Jacobsen L (1960). "Damping in composite structures". Proceedings of Second World Conference on Earthquake Engineering, Tokyo, Japan.

9 Gulkan P and Sozen M (1974). "Inelastic responses of reinforced concrete structures to earthquake motions". ACI Journal, 71(12): 604-610.

10 Applied Technology Council (1996). "ATC-40: Seismic Evaluation and Retrofit of Concrete Buildings". Applied Technology Council, California.

11 Priestley MJN, Calvi GM and Kowalsky M (2007). "Displacement-Based Seismic Design of Structures". Pavia, Italy: IUSS PRESS.

12 Pennucci D, Sullivan TJ and Calvi GM (2011). "Displacement reduction factors for the design of medium and long period structures". Journal of Earthquake Engineering, 15(S1): 1-29. https://doi.org/10.1080/13632469.2011.562073

13 Stafford PJ, Sullivan TJ and Pennucci D (2016). "Empirical correlation between inelastic and elastic spectral displacement demands". Earthquake Spectra, 32(3): 1419-1448. https://doi.org/10.1193/020515EQS021M

14 Sullivan TJ, Calvi GM and Priestley MJN (2004). "Initial stiffness versus secant stiffness in displacement-based design". Proceedings of $13^{\text {th }}$ World Conference on Earthquake Engineering, 1-6 August, Vancouver, Canada, Paper No 2888.

15 Standards New Zealand (2016). "NZS1170.5: Structural Design Actions - Part 5: Earthquake Actions - New Zealand Incorporating Amendment No. 1". Standards New Zealand, Wellington, NZ.

16 Fox MJ (2016). "Simplified Performance-Based Seismic Assessment of RC Wall Buildings". PhD Dissertation, IUSS PRESS, Pavia, 272pp.
17 Rutenberg V and Pekau OA (1987). "Seismic code provisions for asymmetric structures: A re-evaluation". Engineering Structures, 9(4): 255-264. https://doi.org/10.1016/0141-0296(87)90024-1

18 Hatami M, MacRae GA, Rodgers G and Clifton C (2019). "Numerical and experimental study on friction connections performance - Asymmetric and Symmetric (AFC/SFC)". Proceedings of the 2019 Pacific Conference on Earthquake Engineering, 4-6 April, Auckland, NZ.

19 Takeda T, Sozen M and Nielsen N (1971). "Reinforced concrete response to simulated earthquakes". Journal of the Structural Division, ASCE, 96(12): 19-26. https://doi.org/10.1061/JSDEAG.0002765

20 Saiidi M and Sozen M (1979). "Simple and Complex Models for the Nonlinear Seismic Response of Reinforced Concrete Structures". Department of Civil Engineering, University of Illinois, Urbana, Illinois, USA.

21 McKenna F and Fenves G (2000). "Open System for Earthquake Engineering Simulation". University of California: Berkeley, California.

22 Kramer S (1996). "Geotechnical Earthquake Engineering". New Jersey: Prentice Hall.

23 Yeow T, Orumiyehei A, Sullivan TJ, MacRae GA, Clifton C and Elwood K (2018). "Seismic performance of steel friction connections considering direct-repair costs". Bulletin of Earthquake Engineering, 16: 5963-5993. https://doi.org/10.1007/s10518-018-0421-x

24 Chopra A (1995). "Dynamics of Structures". Englewood Cliffs, New Jersey: Prentice-Hall.

25 Pennucci D, Calvi GM and Sullivan TJ (2009). "Displacement-based design of precast walls with additional dampers". Journal of Earthquake Engineering, 13(S1): 40-65. https://doi.org/10.1080/13632460902813265

26 Soleimankhani H (2021). "Accounting for Building Torsional Behaviour during Strong Earthquake Shaking". $\mathrm{PhD}$ Dissertation, University of Canterbury, Christchurch. 